\title{
A term live advanced abdominal pregnancy: a rare case report
}

\section{Seema Sharma*, Hanslata Gehlot, Dinesh Dutt Sharma, Suman Choudhary}

Department of Obstetrics \& Gynaecology, Dr. S. N. Medical College, Jodhpur, Rajasthan, India

Received: 29 January 2016

Revised: 10 March 2016

Accepted: 11 March 2016

\author{
*Correspondence: \\ Dr. Seema Sharma, \\ E-mail: drseemasharma10@outlook.com
}

Copyright: () the author(s), publisher and licensee Medip Academy. This is an open-access article distributed under the terms of the Creative Commons Attribution Non-Commercial License, which permits unrestricted non-commercial use, distribution, and reproduction in any medium, provided the original work is properly cited.

\begin{abstract}
Advanced abdominal pregnancy is a rarely encountered entity. Extra uterine ectopic pregnancy is frequently missed in antenatal period. Here, we report a case of live secondary abdominal pregnancy in a primigravida with period of 37 weeks of gestation. The diagnosis was missed in antenatal period despite regular antenatal check-ups and ultrasound. Patient was managed by exploratory laparotomy, the foetus was extracted out and the placenta was left in situ. Rest of the post-operative period was uneventful. The new born expired in neonatal ward after 24 hours due to hypoplastic lungs. Patient was followed up by serial serum $\beta$ HCG values and serial ultrasonography of maternal abdomen. $\beta$ HCG was negative in three months. Patient is still in follow up period.
\end{abstract}

Keywords: Term abdominal pregnancy, Live foetus, Exploratory laparotomy, Serum $\beta$ HCG

\section{INTRODUCTION}

An abdominal pregnancy is the one which develops in relation with the peritoneal cavity. Abdominal pregnancy constitutes nearly $1 \%$ of all ectopic pregnancies. ${ }^{1}$ Risk factors are same as for ectopic pregnancy such as tubal damage, pelvic inflammatory disease, endometriosis, multiparity and assisted reproductive techniques. ${ }^{2-4}$ Diagnosis of such cases is frequently missed in antenatal period despite routine ultrasound scan. However, its diagnosis is very essential due to the high incidence of maternal morbidity and mortality associated with such cases. Management of such cases depends on the gestation age and the site of attachment of the placenta. Here, we report a case of live secondary abdominal pregnancy in a primigravida with period of 37 weeks gestation. The diagnosis was missed in antenatal period despite regular antenatal check-ups and ultrasound. Patient was managed by exploratory laparotomy.

\section{CASE REPORT}

A 30 years old primigravida with nine months of amenorrhoea presented with complaints pain abdomen for two days, spotting per vaginum for one day and vomiting for one day. Patient's last menstrual period (LMP) was on 18/02/2014. She first consulted obstetrician on 16/04/2014 for complaints of amenorrhea for 2 months with spotting and her first ultrasound scan on the same day was suggestive of missed abortion. Medical termination of Pregnancy (MTP) Pills was prescribed on 17/04/2014, but pregnancy was not terminated and patient chose to continue her pregnancy. Rest of her antenatal period was uneventful. Ultrasonography on 19/07/2014 revealed single live foetus of 20.5 weeks unstable lie, markedly reduced amniotic fluid, grade 0 placenta, EDD on 01/12/2014. A repeat scan on 22/10/2014 revealed live abdominal ectopic pregnancy of gestational age 31.6 weeks, foetus was lying in abdominal cavity outside uterus and placenta in left iliac fossa. Rest of the investigations including hemogram, renal and liver function tests were within normal limits and viral markers were negative (Table 1).

On examination, patient was comfortable, afebrile. Her vitals were pulse rate $-110 / \mathrm{min}$, blood pressure - $120 / 80$ $\mathrm{mm}$ of $\mathrm{Hg}$, afebrile and respiratory rate of $16 / \mathrm{min}$. Cardiovascular and respiratory system were normal on examination. On per abdominal examination (Figure 1), gross foetal movements were appreciable but uterine 
contour was not appreciable. Foetal parts were felt more easily than usual. Foetal heart sound was heard on left side of upper half of abdomen. Per vaginal examination revealed an uneffaced, undilated firm cervix. No bleeding per vaginum. Magnetic Resonance Imaging of abdomen and pelvis (Figure 2) revealed extra uterine pregnancy in abdominal cavity and placenta was situated in left iliac fossa and suprapubic region and abutting mesentery and fundus of uterus. Prominent blood vessels in the parauterine region. Both ovaries were not separately identified. Prominent vessel also seen extending superiorly along left psoas muscle to reach up to splenic and renal vessels from which it appears non separable.

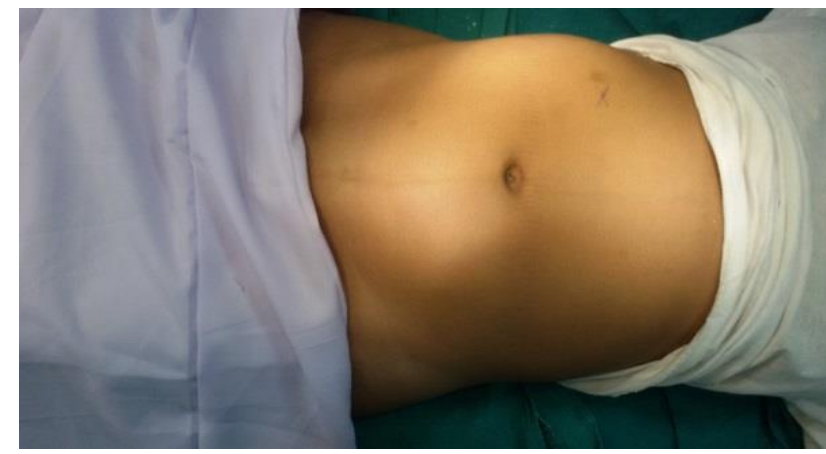

Figure 1: Per abdominal inspection revealing abnormal uterine contour and foetal heart sound marked with cross on right hypochondrial region.

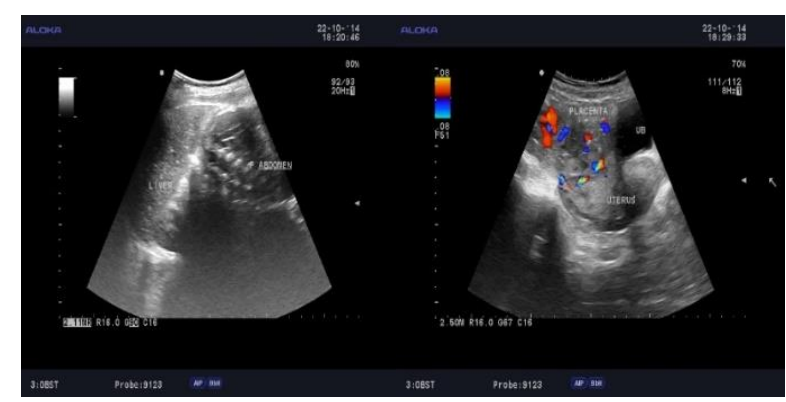

Figure 2: MRI of abdomen and pelvis: Extra uterine pregnancy in abdominal cavity and placenta is situated in left iliac fossa and suprapubic region and abutting mesentery and fundus of uterus. Prominent blood vessels in the parauterine region present. Both ovaries were not separately identified. Prominent vessel also seen extending superiorly along left psoas muscle to reach up to splenic and renal vessels from which it appears non separable.

With informed high risk and written consent, three units of packed cells arranged and general surgeon by side patient was taken for exploratory laparotomy (Figure 3) under spinal anaesthesia. Abdomen was opened up by midline subumblical incision. Foetus was lying in abdominal cavity on the right side; an alive female child weighing $2.5 \mathrm{~kg}$ was delivered out. Placenta was in left lower abdomen involving omentum, small bowel, mesentery and sigmoid colon. Uterus and right adnexa were normal left adnexa had adhesions and placenta was adherent to left adnexa, all forming a mass of size $18 \times$ 20 centimetres occupying left lower abdomen. Placenta was not removed, cord was clamped cut short, and ligated doubly. The neonate (Figure 4) had no specific congenital anomalies except for hypo plastic lungs and expired in neonatal ward due to same reason after $24 \mathrm{hrs}$.

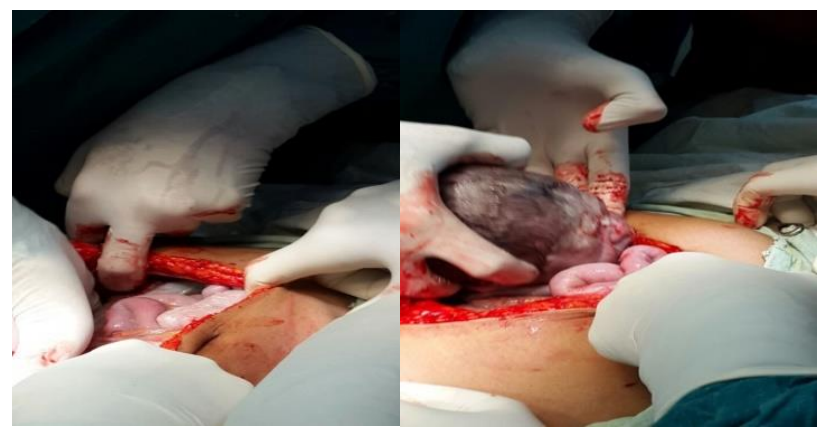

Figure 4: Intraoperative procedure of extracting out the abdominal pregnancy.

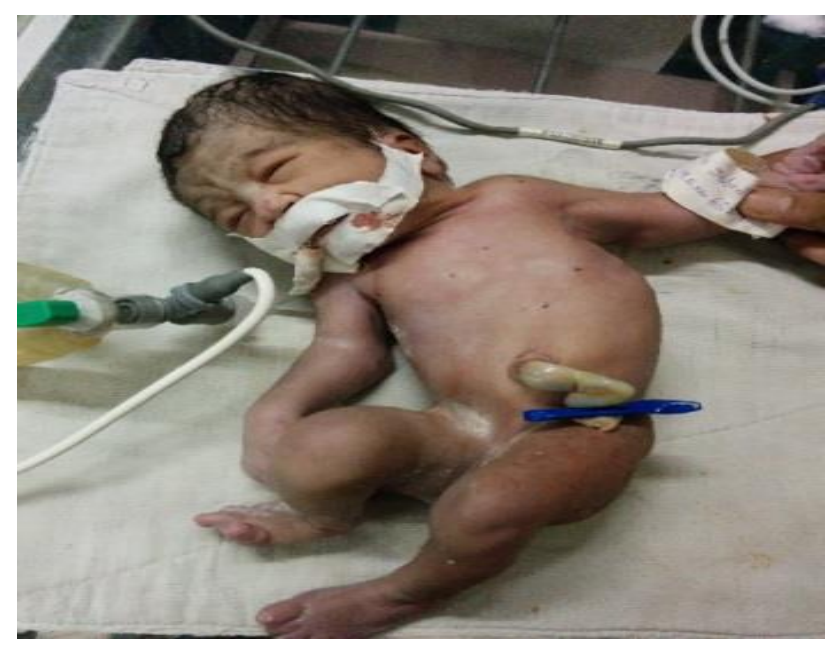

Figure 4: The live new born in neonatal ward.

Post-operative period uneventful. Post operatively patient was followed up by serial serum $\beta$ HCG levels showing decreasing titres and ultrasound of abdomen once in 15 days which showed gradual reduction in size in placental size in subsequent ultrasound pictures (Table 2).

Table 1: Investigations of the patient.

\begin{tabular}{|ll|}
\hline Patient's blood group & A negative \\
\hline Husband blood group & A positive \\
\hline Rh antibody titre & Negative \\
\hline Hemogram & \\
Hb & $11.0 \mathrm{gm} \%$ \\
TLC & $11460 / \mathrm{mm} 3$ \\
Platelets & $3,22,000 / \mathrm{mm} 3$ \\
\hline Coagulation profile & within normal limit \\
\hline RFT & within normal limit \\
\hline LFT & within normal limit \\
\hline
\end{tabular}




\begin{tabular}{|ll|}
\hline HIV & Negative \\
\hline HBsAg & Negative \\
\hline VDRL & non-reactive \\
\hline
\end{tabular}

Table 2: Serial serum $\beta$ HCG and placental size monitoring of the patient.

\begin{tabular}{|lll|}
\hline Date & $\begin{array}{l}\text { Serum } \beta \text { HCG } \\
\text { values } \\
\text { postoperatively }\end{array}$ & $\begin{array}{l}\text { Sive of } \\
\text { placenta }\end{array}$ \\
\hline $26 / 10 / 14$ & post operatively & \\
\hline $1 / 11 / 14$ & $28200 \mathrm{mIU} / \mathrm{ml}$ & $14.0 * 9.0 \mathrm{~cm}^{2}$ \\
\hline $7 / 11 / 14$ & $18400 \mathrm{mIU} / \mathrm{ml}$ & -- \\
\hline $14 / 11 / 14$ & $7600 \mathrm{mIU} / \mathrm{ml}$ & $13.5 * 5.6 \mathrm{~cm}^{2}$ \\
\hline $21 / 11 / 14$ & $5800 \mathrm{mIU} / \mathrm{ml}$ & -- \\
\hline $27 / 11 / 14$ & $3400 \mathrm{mIU} / \mathrm{ml}$ & $12.5 * 5.6 \mathrm{~cm}^{2}$ \\
\hline $4 / 12 / 14$ & $592 \mathrm{mIU} / \mathrm{ml}$ & -- \\
\hline $11 / 12 / 14$ & $163 \mathrm{mIU} / \mathrm{ml}$ & $15.0 * 6.7 \mathrm{~cm}^{2}$ \\
\hline $18 / 12 / 14$ & $140 \mathrm{mIU} / \mathrm{ml}$ & -- \\
\hline $03 / 01 / 15$ & $40 \mathrm{mIU} / \mathrm{ml}$ & $13.6 * 8.0 \mathrm{~cm}^{2}$ \\
\hline $18 / 03 / 15$ & $5.5 \mathrm{mIU} / \mathrm{ml}$ & $13.5 * 8.0 \mathrm{~cm}^{2}$ \\
\hline
\end{tabular}

\section{DISCUSSION}

Abdominal pregnancy is a rare type of ectopic pregnancy. It is of two types, primary abdominal pregnancy is the one which is implanted directly in the abdominal cavity and its organs, except for the tubes and ovaries. It is very rare. Studdiford's criteria for primary abdominal pregnancy include 3 things, viz, tubes and ovaries should be normal, there is no abnormal connection (fistula) between the uterus and the abdominal cavity and pregnancy is related solely to the peritoneal surface without signs that there was a tubal pregnancy first. ${ }^{5}$ Secondary abdominal pregnancy is a more common which is originated from tubal (less commonly an ovarian) pregnancy and aborts backwards down a tube, or bursts out of it without killing the patient, and embeds itself elsewhere in her abdominal cavity. Incidence of abdominal pregnancy is increasing in developing countries probably due to higher incidence of partially treated pelvic inflammatory diseases. ${ }^{6}$ It constitutes nearly $1.4 \%$ of all ectopic pregnancies with a maternal mortality rate of $0.5-18 \%$ and perinatal mortality rate of 40-95\%. ${ }^{7,8}$ Patients may present with complaints of abdominal pain, nausea, vomiting, painful foetal movements, or rarely vaginal bleeding. Classic ultrasound finding is the absence of myometrial tissue between the bladder and pregnancy. ${ }^{9,10}$ Associated morbidity with advanced abdominal pregnancy includes bleeding, infection, anaemia, disseminated intravascular coagulation, pulmonary embolism, and gastrointestinal obstruction or fistulas arising from the presence of foetal bones. 6

Major complications may arise due to the risk of erosion of maternal blood vessels by trophoblastic tissue which can lead to profuse hemorrhage at any stage of pregnancy. At times patient may experience false labor with risk of internal bleeding. Rarely fetus may be small, deformed or may die. Dead fetus may be retained for several years resulting in mummification, calcification or lithopedion formation, or at times sac may get infected from adjacent bowel with expulsion of fetal parts via rectum, bladder, etc. ${ }^{11}$ Birth defects are common in such neonates due to the absence of amniotic fluid which accounts for higher perinatal mortality.

\section{CONCLUSIONS}

Abdominal pregnancy is frequently misdiagnosed even with regular antenatal check-ups and on ultrasound. The rates of maternal mortality and morbidity are very high due to haemorrhage from placental separation and erosion. A high index suspicion is required by the obstetrician to diagnose this condition which can further help in preventing maternal and perinatal morbidity and mortality. Here the case was a secondary abdominal pregnancy which was unfortunately missed during antenatal period, as the Studdiford's criteria was not fulfilled. Exploratory laparotomy is the main treatment modality and it is always better to seek help from more experienced obstetricians. Placenta remains in situ for years. Diagnosing a case of abdominal pregnancy is at times very difficult as it causes comparatively few symptoms and none of them are individually diagnostic. So the diagnosis depends on the sum of many clues, none of which is enough by itself. Serum $\beta$ HCG is useful in follow up period. But placenta remains in situ for years. Foetal malformation is one of the numerous challenges that can confront the new born. Patient is still in follow up period.

\section{ACKNOWLEDGEMENTS}

I acknowledge the help our entire team of obstetricians, operation theatre and ICU staff for their help and cooperation. The woman and her whose story is told in this case report cooperated in our work signed permission for its publication.

\section{Funding: Not required \\ Conflict of interest: None declared \\ Ethical approval: Not required}

\section{REFERENCES}

1. Yildizhan R, Kolusari A, Adali F, Adali E, Kurdoglu M. Primary abdominal ectopic pregnancy: a case report. Cases Journal. 2009;2:8485.

2. Binder DS. Thirteen-week abdominal pregnancy after hysterectomy. Journal of Emergency Medicine. 2003;25(2):159-61.

3. Fader AN, Guido RS, Wiesenfeld HC. A 14-week abdominal pregnancy after total abdominal hysterectomy. Obstetrics and Gynecology. 2007;109(2):519-21.

4. Varma R, Mascarenhas L, James D. Successful outcome of advanced abdominal pregnancy with 
exclusive omental insertion. Ultrasound in Obstetrics and Gynecology. 2003;21(2):192-4.

5. Studdiford WE. Primary peritoneal pregnancy. Am J Obstet Gynecol. 1942;44:487-91.

6. Riethmuller D, Courtois L, Maillet R, Schaal JP. Ectopic pregnancy management: cervical and abdominal pregnancies. J Gynecol Obstet Biol Reprod (Paris). 2003;32(7 Suppl):S101-8.

7. Atrash HK, Friede A, Hogue CJ. Abdominal pregnancy in the United States: frequency and maternal mortality. Obstet Gynecol. 1987;69(3 Pt 1):333-7.

8. Martin JN Jr, Sessums JK, Martin RW, Pryor JA, Morrison JC. Abdominal pregnancy: current concepts of management. Obstet Gynecol. 1988;71(4):549-57.
9. Allibone GW, Fagan CJ, Porter SC. The sonographic features of intra-abdominal pregnancy. J Clin Ultrasound. 1981;9(7):383-7.

10. Angtuaco TL, Shah HR, Neal MR, Quirk JG. Ultrasound evaluation of abdominal pregnancy. Crit Rev Diagn Imaging. 1994;35(1):1-59.

11. Irick MB, Kitsos CN, O'Leary JA. Therapeutic aspects in the management of a lithopedion. Am Surg. 1970; 36:232-4.

Cite this article as: Sharma S, Gehlot $\mathrm{H}$, Sharma DD, Choudhary S. A term live advanced abdominal pregnancy: a rare case report. Int J Reprod Contracept Obstet Gynecol 2016;5:1233-6. 